\title{
Influence of the treatment with the antineoplastic agents 5-fluorouracil and Cisplatin on the severity of experimental periodontitis in rats
}

\author{
vivian novaes ( $\square$ vcnnovaes@hotmail.com ) \\ UNESP: Universidade Estadual Paulista Julio de Mesquita Filho https://orcid.org/0000-0003-0641-0046

\section{Edilson Ervolino} \\ UNESP: Universidade Estadual Paulista Julio de Mesquita Filho \\ Giovani Lopes Fernandes \\ UNESP: Universidade Estadual Paulista Julio de Mesquita Filho \\ Clara Possarle Cunha \\ UNESP: Universidade Estadual Paulista Julio de Mesquita Filho

\section{Leticia Helena Theodoro} \\ UNESP: Universidade Estadual Paulista Julio de Mesquita Filho \\ Valdir Gouveia Garcia \\ UNESP: Universidade Estadual Paulista Julio de Mesquita Filho \\ Juliano Milanezi de Almeida \\ UNESP: Universidade Estadual Paulista Julio de Mesquita Filho
}

\section{Research Article}

Keywords: Antineoplastic agents, Fluorouracil, Cisplatin, Periodontitis, Alveolar bone loss

Posted Date: May 4th, 2021

DOI: https://doi.org/10.21203/rs.3.rs-390658/v1

License: (c) (i) This work is licensed under a Creative Commons Attribution 4.0 International License. Read Full License

Version of Record: A version of this preprint was published at Supportive Care in Cancer on October 11th, 2021. See the published version at https://doi.org/10.1007/s00520-021-06586-y. 


\section{Abstract \\ Purpose}

The determination on how antineoplastic agents interfere on the progression of periodontitis is critical for improvement and even development of novel therapeutic approaches for periodontal management. This study evaluated the influence of chemotherapy with 5-fluorouracil (5-FU) or cisplatin (CIS) on healthy periodontal tissues and on the progression of experimental periodontitis (EP).

\section{Methods}

One-hundred-forty-four male rats were divided into six groups $(n=24)$. Each group was treated with physiological saline solution (PSS) $0.9 \%, 5$-FU or CIS. Experimental periodontitis (EP) was induced by ligature placement. Animals were euthanized at 7,15 and 30 days after treatment. Data were statistically analyzed $(p \leq 0.05)$.

\section{Results}

The groups with EP and treated with 5-FU or CIS showed lower percentage of bone volume in the furcation region and higher percentage of alveolar bone loss, higher number of TRAP-positive cells and lower number of PCNApositive cells when compared group with EP and treated with PSS $(p \leq 0.05)$. Groups with EP and treated with 5-FU or CIS showed high immunolabelling pattern of RANKL, TNF-a, IL-1 $\beta$, moderate of BAX and low of HIF-1a. Histological analysis showed severe tissue breakdown in the groups with EP and treated with 5-FU or CIS.

\section{Conclusions}

Chemotherapy with antineoplastic agents 5-FU and CIS increasing the intensity and duration of the inflammation; and compromising tissue repair by reduction in cellular and vascular turnover. The more severe periodontal breakdown was caused by 5-FU.

\section{Introduction}

Periodontitis is the consequence of the hosts' immunoinflammatory response to periodontopathogens, and its' progression can be modified by local and systemic factors [1]. Immunoinflammatory reactions are the host defense mechanism for prevention of microbial invasion, however, the implications of this cascade of reactions are connective tissue disruption and alveolar bone loss [1, 2]. Hence, drugs interacting with hosts' response to threads may have an impact on the progression of periodontitis $[3,4]$. Antineoplastic agents used for the treatment of cancer aroused interest in periodontics due to their tangible influence on the pathogenesis of periodontitis. Most of these agents display cytotoxic and cytostatic effects, aiming apoptosis or prevention of rapid proliferation of cancer cells $[5,6]$. However, their lack of specificity affects not only cancer cells, but also cells with high mitotic rates [6], such as oral cavity ones [7].

5-Fluorouracil (5-FU) and Cisplatin (CIS) are drugs widely used in the treatment of different types of carcinomas due to their broad antineoplastic activity $[8,9]$. 5-FU is an antimetabolite that inhibits DNA synthesis by blocking thymidylate synthase production and by incorporating its metabolites into RNA and DNA [10]. CIS is an alkylating 
agent that induces chromatin internucleosomal cleavage resulting in cellular apoptosis [11]. Among the limited experimental studies [12-14] evaluating the influence of 5-FU on periodontitis, is reported increased destruction of the alveolar bone in the furcation, higher inflammatory infiltrate, and higher RANKL immunolabelling [12, 13]. Data have shown the negative impact of 5 -FU on the development of experimental periodontitis (EP). Furthermore, 5-FU negatively affected the periodontal repair following scaling and root planning (SRP) [12]. With regard to CIS, recent experimental research reported exacerbation of periodontal inflammation in the early periods of EP [15].

However, there are still limited evidences to clarify the influence of chemotherapy as a modifying factor in the progression of periodontitis. Our null hypothesis would be no influence of 5-FU or CIS in the progression of EP. Thus, the aim of this study was to comparatively evaluate the effects of the treatment with the antineoplastic agents 5-FU and $\mathrm{CIS}$ on healthy periodontal tissues and on the progression of EP in the furcation region of the rats' first lower molars.

\section{Materials And Methods}

\subsection{Animals and sample calculation}

One hundred fourty four adult male rats (Rattus norvegicus, albinus, Wistar), weighing between 250 and $300 \mathrm{~g}$ were used in this study. All protocols were approved by Ethics Committee in Animal Use (\#2014/00543) of the School of Dentistry of Araçatuba, São Paulo State University (UNESP). This study is in accordance with the Reporting animal research: Explanation and elaboration for the ARRIVE guidelines 2.0 [16].

Sample size was calculated based on previous histometric data $[12,19,20]$ in order to achieve a 0.90 power and 0.05 alpha error based on a $10 \%$ potential standard deviation and the assumption that $10 \%$ difference between groups/periods would be relevant. Based on this, 8 rats per group/period for the percentage of alveolar bone loss (PABL) and immunohistochemistry were enough to reject the null hypothesis.

\subsection{Experimental Groups}

The animals were numbered sequentially from 1 to 144 and the experimental groups assigned as NEP-PSS, EP-PSS, NEP-5FU, EP-5-FU, NEP-CIS e EP-CIS (7, 15 and 30 days). These data were uploaded to the software Minitab ${ }^{\circledR} 17$ (Minitab Inc. State College, PA, USA), which was used to randomize the animals to each experimental group/period (1:1 allocation ratio)

Groups $(n=24)$ NEP-PSS and EP-PSS were treated with physiological saline solution $0.9 \%$ (PSS). NEP-5FU and EP$5 F U$ were treated with 5-FU, and NEP-CIS and EP-CIS were treated with CIS. Each animal received two intraperitoneal injections of either PSS (Equiplex Indústria Farmacêutica, Aparecida de Goiânia, GO, Brazil), 5-FU (Fluorouracila, 250 $\mathrm{mg} / 10 \mathrm{~mL}$, Eurofarma Laboratórios, São Paulo, SP, Brazil) or CIS (Fauldcispla, $10 \mathrm{mg} / 10 \mathrm{ml}$, Libbs Farmacêutica, São Paulo, SP, Brazil) at day 0 (5-FU, $60 \mathrm{mg} / \mathrm{Kg} ; \mathrm{ClS}, 5 \mathrm{mg} / \mathrm{Kg}$ ) and day 2 (48 h later) (5-FU, $40 \mathrm{mg} / \mathrm{Kg} ; \mathrm{ClS}, 2,5$ $\mathrm{mg} / \mathrm{Kg}$ ), in accordance with Gusman et al. (2018) [15].

At day 0, after general anesthesia (cloridrato de cetamina - $70 \mathrm{mg} / \mathrm{Kg}$ [Syntec, Santana de Parnaíba, SP, Brazil], cloridrato de xilazina - $6 \mathrm{mg} / \mathrm{Kg}$ [Syntec, Santana de Parnaíba, SP, Brazil], intramuscular injection), a \#24 (Corrente Algodão $n^{\circ} 24$, Coats Corrente, São Paulo, SP, Brazil) cotton thread was placed around both lower first molars to induce EP in groups EP-PSS, EP-5FU and EP-CIS $[17,18]$.

\subsection{Experimental periods}


Eight animals per group/period were euthanized with an overdose $(150 \mathrm{mg} / \mathrm{kg})$ of thiopental (Cristália, Ltda., Itapira, SP, Brazil) at 7, 15 and 30 days after EP induction. The mandible was removed, separated at the median plane, and the hemimandibles fixed in $4 \%$ buffered formaldehyde for 48 hours.

\subsection{Laboratory Processing}

Micro computed tomography $(\mu \mathrm{CT})$ of bone volume fraction

Randomly selected non-demineralized hemimandibles were scanned by X-ray microtomograph SkyScan (SkyScan 1176 Bruker MicroCT, Aatselaar, Belgium, 2003) with a voxel size of $18 \mu \mathrm{m}(50 \mathrm{Kv}$ e $500 \mu)$ for cone-beam microcomputed tomography $(\mu \mathrm{CT})$.

\subsubsection{Tissue processing}

The contralateral hemimandibles to those selected for $\mu$ CT were demineralized in $10 \%$ ethylenediaminetetraacetic acid (EDTA) for 60 days. After demineralization, were processed and embedded in paraffin. Semi-serial histologic sections $(4 \mu \mathrm{m})$ were obtained of the central furcation region from buccal to lingual progression. Five equidistant histologic sections from each specimen were stained with hematoxylin and eosin (HE) for histologic and histometric analyses. Eight additional sections were subjected to the indirect immunoperoxidase method according to the protocol described by Matheus et al., (2018) ${ }^{21}$ for detection of tartrate-resistant acid phosphatase (TRAP) (SC 30833, Santa Cruz Biotecnology, Santa Cruz, CA, EUA), receptor activator of nuclear factor kappa-B ligand (RANKL) (SC 7628, Santa Cruz Biotecnology, Santa Cruz, CA, EUA), osteoprotegerin (OPG) (SC 7628, Santa Cruz Biotecnology, Santa Cruz, CA, EUA), tumor necrosis fator-alfa (TNF-a) (SC-1348, Santa Cruz Biotechnology, Santa Cruz, CA, USA), interleukin 1 beta (IL-1 $\beta$ ) (SC-7884, Santa Cruz Biotechnology, Santa Cruz, CA, USA), proliferating cell nuclear antigen (PCNA) (VP-P980, Vector Laboratories, Burlingame, CA, EUA), bcl-2-associated X protein (BAX) (SC-526, Santa Cruz Biotechnology, Santa Cruz, CA, USA) and hypoxia-inducible factor 1 alpha (HIF-1a) (usc-53546, Santa Cruz Biotechnology, Santa Cruz, CA, USA).

\subsection{Analysis of the results}

All examiners were trained, calibrated and masked to the experimental groups.

\subsubsection{Micro-CT analysis}

The images recorded by the microtomographic scanning were sequentially reconstructed, spatially reoriented, and analyzed using appropriate software (NRecon/DataViewer/CTAN;Skyscan). The percentage of bone tissue volume (PBTV) in the furcation of the lower first molars was measured [22]. In each image correspondent to the center of the furcation, the volume of interest (VOI) was standardized according to the following criteria: apical limit, apex of the mesial and distal roots; coronal limit, roof of the furcation; posterior limit, mesial side of the distal root; anterior limit, distal side of the mesial root. Within VOI, the volume mineralized tissues (VMT) were detected and the equation VMT×100/VOI was used to calculate the PBTV.

\subsubsection{Histometric analysis}

The percentage of alveolar bone loss (PABL) in the furcation was analyzed using a method adapted from Garcia et al., (2015) [12]. An imaging analysis system was used (Axiovision 4.8.2, Carl Zeiss Microlmaging GmbH, 07740 Jena, Germany) to delineate the entire furcation area (FA) in $\mathrm{mm}^{2}$. Within FA was delineated the bone area (BA), also in $\mathrm{mm}^{2}$. The percentage of bone in the furcation (PBF) was calculated by the equation BA×100/FA. Then, PBFA was 
determined by subtracting PBF from 100. Three distinct measurements were performed within a one-week interval in order to access the accordance among measurements.

\subsubsection{Histologic analysis}

Histologic analysis was performed by a certified histologist (EE) according to the following parameters [20, 23]: 1) intensity of local inflammatory response; 2) extension of inflammatory infiltrate; 3) external root resorption (cementum and dentin); 4) alveolar bone resorption; 5) pattern of the connective tissue structure; and 6) pattern of the alveolar bone structure.

\subsubsection{Immunohistochemical analysis}

The sections were analyzed under bright field illumination of an optical microscope (Optiphot-2, Nikon, Japan). Immunolabelling for RANKL, OPG, TNFa, IL-1ß, BAX e HIF-1a was analyzed in AF at x 400 magnification. Immunolabelling for TRAP and PCNA was assessed by quantification of TRAP- and PCNA-positive cells within a $1000 \mu \mathrm{m} \times 1000 \mu \mathrm{m}$ area in the center of the interradicular septum, at x 200 magnification [24, 25].

\subsubsection{Primary and secondary outcomes}

The primary outcome was defined as the presence or absence bone within the region of interest. PABL and PBTV were considered the primary outcome variables. The secondary outcome was to define the cellular events (tissue response and immunolabelling patterns) occurring in the furcation of all experimental groups over time.

\subsubsection{Statistical analysis}

Data were analyzed using the software Bioestat 5.0 (Bioestat 5.0, Sociedade Civil de Mamirauá, Belém, PA, Brazil). Cohen's kappa coefficient was used to calculate the agreement among the measurements of PABL. The normality of the PABL, PBTV, TRAP and PCNA were analyzed using the Shapiro-Wilk test, then submitted one-way ANOVA followed by Tukey's post-test ( $p \leq 0.05)$.

\section{Results}

\subsection{PBTV Micro-CT analysis}

Lower PBTV were observed in EP-5FU when compared with EP-PSS and EP-CIS in all experimental periods. Also, lower PBTV was observed in EP-CIS when compared to EP-PSS at 15 and 30 days ( $\leq \leq 0.01$ ) (Figure 1).

\subsection{PABL analysis}

Higher PABL was observed in EP-PSS, EP-5FU and EP-CIS when compared with NEP-PSS, NEP-5FU and NEP-CIS $(p \leq 0.01)$. EP-5FU and EP-CIS showed higher PABL when compared with EP-PSS in all experimental periods $(p \leq 0.05)$. EP-5FU showed higher PABL when compared with EP-CIS at 7 and 15 days ( $p \leq 0.05)$ (Figure 2).

\subsection{Histological analysis}

NEP-PSS, NEP-5FU and NEP-CIS exhibited histopathological features similar among groups and consistent with normality. EP-PSS showed intense inflammatory infiltrate within the connective tissue in the furcation area at 7 days. The magnitude and extent of the inflammatory response gradually decreased over time. Some specimens had necrotic bone spicules. The interradicular septum presented irregular contour with thin bone trabeculae and persistent active osteoclasts in all experimental periods. The intense inflammatory infiltrate in the connective tissue 
reached the bone margins of the interradicular septum in groups EP-5FU and EP-CIS at 7, 15 and 30 days. In most specimens, large necrotic bone spicules were present. The bone tissue of the interradicular septum presented very thin bone trabeculae, with large medullary spaces and infiltration of including inflammatory cells. The outer contour of the interradicular septum was very irregular, full of resorption lacunae and active osteoclasts. In some specimens, especially from EP-5FU at 15 and 30 days and EP-CIS 30 days, the stage of bone resorption was so pronounced that it completely eliminated the interradicular septum and reached the basal bone of the mandible, indicating an increased severity of periodontitis over time. EP-5FU showed accelerated periodontal disruption when compared with EP-CIS. (Table 1).

\subsection{Immunohistochemical analysis}

Immunohistochemistry yielded high specificity to the biomarkers, confirmed by the brownish color present predominantly in the cytosolic compartment and poorly in the extracellular matrix for RANKL, OPG, TNFa, IL-1 $\beta, B A X$ e HIF-1a, confined to cytosolic compartment for TRAP, and confined to the nucleus to PCNA.

TRAP-positive cells were predominantly osteoclasts, had more than three nuclei and were attached to the alveolar bone surface of the interradicular septum. EP-5FU showed higher number of TRAP-positive cells when compared with EP-PSS in all experimental periods $(p \leq 0.05)$. EP-CIS presented higher number of TRAP-positive cells when compared with the EP-PSS at 7 and 15 days $(p \leq 0.05)$. The intragroup comparation showed higher number of TRAPpositive cells at 7 days when compared with 15 and 30 days in groups EP-5FU and EP-CIS. ( $\mathrm{p} \leq 0.01)$ (Figure 3A through $3 \mathrm{~K})$.

RANKL (Figure 3L through 3N) and OPG (Figure 3P through 3Q) immunolabelling was mainly expressed in osteoblasts and some fibroblasts in bone and connective tissue in the furcation region. EP-5FU and EP-CIS presented extremely high to high RANKL immunolabelling pattern, while EP-PSS presented high to moderate immunolabelling pattern over the time. For OPG immunolabelling, NEP-PSS and EP-PSS ranged from low to moderate patterns in all experimental periods. All groups treated with antineoplastic agents presented low immunolabelling pattern for OPG in all experimental periods.

For TNFa (Figure 4A through 4C) and IL-1 $\beta$ (Figure 4D through 4F), NEP-5FU, NEP-CIS, EP-5FU and EP-CIS presented higher immunolabelling pattern when compared with NEP-PSS and EP-PSS. NEP-5FU and NEP-CIS presented predominantly moderate immunolabelling pattern in all experimental periods, while NEP-PSS presented predominantly low immunolabelling pattern in all experimental periods. EP-5FU and EP-CIS presented predominantly high immunolabelling pattern for TNFa and IL-1 $\beta$ in all experimental periods, while in EP-PSS it ranged from moderate to high at 7 and 15 days, and moderate at 30 days.

PCNA immunolabelling (Figure 5A through 5D) was mainly expressed in cells within the connective tissue and on the surface of bone. The intragroup comparison showed higher number of PCNA-positive cells at 7 days when compared with 15 and 30 days ( $\mathrm{p} \leq 0.05$ ) in NEP-5FU, EP-5FU and NEP-CIS, and higher number of PCNA-positive cells at 7 days when compared to 30 days $(p \leq 0.05)$ in EP-CIS. At 15 days, EP-PSS, EP-CIS and NEP-5FU presented higher number of PCNA-positive cells when compared with 30 days $(p \leq 0.05)$. The intergroup comparison showed higher number of PCNA-positive cells in NEP-PSS when compared with NEP-5FU and NEP-CIS in all experimental periods, and lower number of PCNA-positive cells when compared with EP-PSS at 30 days $(p \leq 0.05)$. EP-PSS presented higher number of PCNA-positive cells when compared with NEP-5FU, NEP-CIS, EP-5FU and EP-CIS in all experimental periods $(p \leq 0.05)$. EP-CIS, when compared with NEP-5FU, presented the highest number of PCNA-positive cells at 15 days and the lowest at 30 days $(p \leq 0.05)$. 
For BAX (Figure 5H through 5J), groups NEP-PSS, NEP-5FU, NEP-CIS and EP-PSS presented low immunolabelling pattern in all experimental periods. In EP-5FU and EP-CIS, BAX immunolabelling ranged from low to moderate at 7, 15 and 30 days. For HIF-1a (Fig. 5E through 5G), only the EP-PSS presented moderate immunolabelling pattern in all periods. All other groups presented low immunolabelling pattern independent on experimental period.

\section{Discussion}

The aggravation of EP in animals treated with either 5-FU or CIS as compared with controls rejected our null hypothesis. When compared with each other, the periodontal breakdown in sites with EP in animals treated with 5-FU was significantly higher than CIS.

Alveolar bone loss, the primary outcome of the present research and one of the main parameters for evaluation of the severity of EP, was accessed through the analyses of PBTV and PABL. Collectively, it was observed higher bone loss in groups EP-5FU and EP-CIS when compared with EP-PSS. These results corroborate with other researches reporting that 5-FU causes extensive resorption of the alveolar bone in the furcation region of animals with EP [12, $13,18,19]$. In addition, our results reported more bone loss in animals receiving 5-FU than animals receiving CIS.

The immunohistochemistry for detection of regulators of bone metabolism detected higher number of TRAP-positive cells was found in groups EP-5FU and EP-CIS. Also, EP-5FU and EP-CIS displayed higher RANKL and lower OPG immunolabelling when compared with EP-PSS at the same time points. Even not statistically significant, the higher number TRAP-positive cells in EP-5FU at 7 days suggests increased osteoclasts' activity in the initial periods of EP in this group. Previous studies have shown that animals receiving 5-FU presented higher RANKL immunolabelling, consistent with higher alveolar bone resorption $[12,13]$. Thus, the results presented by this research indicate that both 5-FU and CIS increase the osteoclast activity through activation of the RANK/RANKL system, and, negatively affect the progression of EP.

The proinflammatory cytokines TNF- $\alpha$ and IL-1 $\beta$ stimulate the release of chemokines, induce the expression of inflammatory mediators that amplify the inflammatory response, and also play important a role as positive regulators of bone resorption [26]. Raghu Nadhanan et al. demonstrated that 5-FU induces an inflammatory condition with increased expression of TNF-a and RANK in rats' tibial metaphysis [27]. This environment increased the recruitment of osteoclasts and bone resorption in the area. Similarly, Stine et al. reported the native impact of CIS on the repair process of defects created in tibiae of rats [28]. In our results, groups EP-5FU and EP-CIS presented exacerbation of the inflammatory process when compared with EP-PSS. The same result was found in previous studies evaluating 5-FU and EP [12-14]. Moreover, the present study demonstrated accelerated periodontal breakdown in group EP-5FU when compared with EP-CIS. In agreement with the histologic analysis, the immunohistochemistry for the proinflammatory cytokines showed reduction in the immunolabelling pattern of TNF-a and IL-1 $\beta$ in group EP-PSS over time, while EP-5FU and EP-CIS remained with high immunolabelling pattern of both biomarkers in all experimental periods. These results combined with the histologic findings demonstrate that antineoplastic agents exacerbate and persist the inflammatory response provoked by pathogens in periodontal tissues. Therefore, it can be inferred that the more significant alveolar bone loss in groups treated with either CIS or 5 -FU is a result of the exacerbation of the inflammation. This mechanism can be explained by disruption of connective and bone tissue mediated by the upregulation of TNF- $a$ and IL-1 $\beta$ [29-31]. 5-FU and CIS are known to induce increased expression of proinflammatory cytokines in the intestinal mucosa [32], oral mucosa [33] and kidney [34]. Hamouda et al. [32] observed that 5-FU increased the expression of TNF-a and IL-1 $\beta$ in intestinal mucosa, which degraded the epithelial barrier. Importantly, our study showed higher immunolabelling pattern of TNF-a and IL-1 in NEP-5FU and NEP-CIS when compared with NEP-PSS. This result represents increased expression of 
proinflammatory cytokines in healthy periodontal tissues and corroborates with Gusman et al. 2019 [15], that while assessing the influence of 5-FU and CIS on healthy periodontium at 3, 5 and 7 days, also observed higher immunolabelling pattern of TNF- $\alpha$ and IL-1 $\beta$.

Both 5-FU and CIS have anti-proliferative and apoptotic properties [6, 35, 36]. PCNA is a DNA replication-linked nuclear protein found during cellular division process. This protein plays a role in the initiation of cellular proliferation by increasing the expression of DNA polymerase [37]. BAX is a pro-apoptotic regulator that binds to Bcell lymphoma protein (BCL) -2 and leads to cell death [38]. In the present study, it was observed that, in the EP-5FU and EP-CIS, the number of PCNA-positive cells significantly decreased over time. The interrelation between the lower number of PCNA-positive cells and the higher immunolabelling pattern of BAX in groups EP-5FU and EP-CIS when compared with EP-PSS infers that antineoplastic agents jeopardized tissues' turnover by decreasing cell proliferation and increasing apoptosis. These data are substantiated by other studies that reported the negative impact of chemotherapy on tissues' metabolism [12, 13, 28, 39]. Also, is important to highlight that the lower number of PCNApositive cells in groups NEP-5FU and NEP-CIS, when compared with NEP-PSS, indicates a negative impact of both antineoplastic agents on healthy periodontal tissues, and, combined with the increased expression of proinflammatory cytokines, could plausibly lead to future damages to the periodontium even in the absence of periodontitis.

In addition, our study assessed HIF-1a, a biomarker of tissue hypoxia [40] related to the repair process. Hypoxia is a stimulus for angiogenesis through activation of HIF-1a [41, 42]. HIF-1a increases gene expression of vascular endothelial growth factor (VEGF), a regulator of both angiogenesis and repair process [41]. Our results reported moderate immunolabelling pattern of HIF-1a in group EP-PSS, while in other groups the immunolabelling was strictly low. Therefore, these results support that in groups EP-5FU and EP-CIS the repair process is also harmed by reduction on the angiogenic stimulus.

In our study it was observed that both 5-FU and CIS aggravated the severity of EP through two paths: increasing the intensity and duration of the inflammatory process; and compromising tissue repair by reduction in cellular and vascular turnover. Having in mind that the pathogenesis of periodontal diseases is modified by hosts' immune and inflammatory systems $[30,43]$, the determination on how antineoplastic agents used for the treatment of cancer interfere on the progression of periodontitis is critical for improvement and even development of novel therapeutic approaches for periodontal management.

Based on our results, it can be concluded that both antineoplastic agents 5-FU and CIS aggravate the severity of EP. The more severe periodontal breakdown was caused by 5-FU. However, neither of the tissue alterations induced by 5FU or CIS resulted in alveolar bone loss in healthy periodontium.

\section{Declarations}

\section{ACKNOWLEDGEMENTS}

The authors thank the Periodontics Division, the Department of Basic Sciences of the School of Dentistry, São Paulo State University (Unesp), Araçatuba, São Paulo, Brazil, and São Paulo State University (Unesp), School of Veterinary Medicine, Araçatuba. The authors also thank CAPES for providing scholarship to Dr. Vivian Novaes, and São Paulo State Foundation for Research (FAPESP) for the research grant conceded to Dr. Juliano Milanezi de Almeida (\#2014/11427-8). Also, Clara Possarle Cunha (\#2015/21332-7) and Giovani Lopes Fernandes (\#2015/04639-1) received scholarships from FAPESP. 
Funding: Dr. Juliano Milanezi de Almeida received a grant from the São Paulo State Foundation for ResearchFAPESP (\#2014/11427-8).

Conflicts of interest/Competing interests: The authors report no conflicts of interest related to this study. It was conducted at the Department of Diagnosis and Surgery - Periodontics Division, São Paulo State University (Unesp), School of Dentistry, Araçatuba, São Paulo, Brazil.

Availability of data and material: my manuscript has data included as electronic supplementary material if necessary.

Code availability: N/A

Authors' contributions: VCNN, EE, and JMA have made substantial contributions to conception and design of the study. GLF and CPC have been involved in animal surgery, laboratory processing and data collection. VCNN have been involved in conception, study design, animal surgery, laboratory processing, data interpretation and drafting the manuscript. EE have been involved in study design, histological and immunohistochemical analysis and critically revised the manuscript. JMA have been involved in conception, study design, data interpretation, statistical procedures and critically revised the manuscript. LHT and VGG have critically revised the manuscript. All authors have given final approval of the version to be published.

Ethics approval: All protocols were approved by Ethics Committee in Animal Use (\#2014/00543) of the School of Dentistry of Araçatuba, São Paulo State University (UNESP).

\section{Consent to participate: N/A}

Consent for publication: This manuscript has only been submitted to this journal. It was read and approved by all authors and, if accepted, it will not be published elsewhere in the same form, in English or in any other language, without the written consent of the copyright-holder.

\section{References}

1. Schenkein HA (2006) Host responses in maintaining periodontal health and determining periodontal disease. Periodontol 2000 40:77-93. https://doi.org/10.1111/j.1600-0757.2005.00144.x

2. Cekici A, Kantarci A, Hasturk H, Van Dyke TE (2014) Inflammatory and immune pathways in the pathogenesis of periodontal disease. Periodontol 2000 64:57-80. https://doi.org/10.1111/prd.12002

3. Nassar PO, Nassar CA, Guimarães MR, Aquino SG, Andia DC, Muscara MN, Spolidorio DMP, Rossa C Jr, Spolidorio LC (2009) Simvastatin therapy in cyclosporine A-induced alveolar bone loss in rats. J Periodontal Res 44:479-488. https://doi.org/10.1111/j.1600-0765.2008.01143.x

4. Fernandes LA, de Almeida JM, Theodoro LH, Bosco AF, Nagata MJH, Martins TM, Okamoto T, Garcia VG (2009) Treatment of experimental periodontal disease by photodynamic therapy in immunosuppressed rats. J Clin Periodontol 36:219-228. https://doi.org/10.1111/j.1600-051X.2008.01355.x

5. Guchelaar HJ, Vermes I, Koopmans RP, Reutelingsperger CP, Haanen C (1998) Apoptosis- and necrosis-inducing potential of cladribine, cytarabine, cisplatin, and 5-fluorouracil in vitro: a quantitative pharmacodynamic model. Cancer Chemother Pharmacol 42:77-83. https://doi.org/10.1007/s002800050788

6. Arias JL (2008) Novel strategies to improve the anticancer action of 5-fluorouracil by using drug delivery system. Molecules 13:2340-2369. https://doi.org/10.3390/molecules13102340 
7. Wong HM (2014) Oral complications and management strategies for patients undergoing cancer therapy. ScientificWorldJournal 2014:581795. https://doi.org/10.3390/molecules13102340

8. Lorch JH, Goloubeva O, Haddad RI, Cullen K, Sarlis N, Tishler R, Tan M, Fasciano J, Sammartino DE, Posner MR, TAX 324 Study Group (2011) Induction chemotherapy with cisplatin and fluorouracil alone or in combination with docetaxel in locally advanced squamous-cell cancer of the head and neck: long-term results of the TAX 324 randomised phase 3 trial. Lancet Oncol 12:153-159. https://doi.org/10.1016/S1470-2045(10)70279-5

9. Vermorken JB, Peyrade F, Krauss J, Mesía R, Remenar E, Gauler TC, Keilholz U, Delord JP, Schafhausen P, Erfán J, Brümmendorf TH, Iglesias L, Bethe U, Hicking C, Clement PM (2014) Cisplatin, 5-fluorouracil, and cetuximab (PFE) with or without cilengitide in recurrent/metastatic squamous cell carcinoma of the head and neck: results of the randomized phase I/II ADVANTAGE trial (phase II part). Ann Oncol 25:682-688.

https://doi.org/10.1093/annonc/mdu003

10. Longley DB, Harkin DP, Johnston PG (2003) 5-fluorouracil: mechanisms of action and clinical strategies. Nat Rev Cancer 3:330-338. https://doi.org/10.1038/nrc1074

11. Havelka AM, Berndtsson M, Olofsson MH, Shoshan MC, Linder S (2007) Mechanisms of action of DNAdamaging anticancer drugs in treatment of carcinomas: is acute apoptosis an "off-target". effect? Mini Reviews in Medicinal Chemistry 7:1035-1039. https://doi.org/10.2174/138955707782110196

12. Garcia VG, Novaes VC, De Almeida JM, Longo M, Ervolino E, Bomfim SRM, Theodoro LH (2015) Evaluation of the progression and treatment of experimental periodontitis in rats subjected to chemotherapy with 5fluorouracil. Support Care Cancer 23:2007-2017. https://doi.org/ 10.1007/s00520-014-2563-y

13. Theodoro LH, Longo M, Ervolino E, Duque C, Ferro-Alves ML, Assem NZ, Louzada LM, Garcia VG (2016) Effect of low-level laser therapy as an adjuvant in the treatment of periodontitis induced in rats subjected to 5-fluorouracil chemotherapy. J Periodontal Res 51:669-680. https://doi.org/10.1007/s00520-014-2563-y

14. Theodoro LH, Longo M, Novaes VCN, Miessi DMJ, Ferro-Alves E, de Almeida JM, Garcia VG (2017) Low-level laser and antimicrobial photodynamic therapy on experimental periodontitis in rats submitted to chemotherapy by 5-fluorouracil. Support Care Cancer 25:3261-3271. https://doi.org/10.1007/s00520-017-3738-0

15. Gusman DJR, Ervolino E, Theodoro LH, Garcia VG, Nagata MJH, Alves BES, de Araujo NJ, Matheus HR, de Almeida JM (2019) Antineoplastic agents exacerbate periodontal inflammation and aggravate experimental periodontitis. J Clin Periodontol 46:457-469. https://doi.org/10.1111/jcpe.13101

16. Percie du Sert N, Ahluwalia A, Alam S, Avey MT, Baker M, Browne WJ, Clark A, Cuthill IC, Dirnagl U, Emerson M, Garner P, Holgate ST, Howells DW, Hurst V, Karp NA, Lazic SE, Lidster K, MacCallum CJ, Macleod M, Pearl EJ, Petersen OH, Rawle F, Reynolds P, Rooney K, Sena ES, Silberberg SD, Steckler T, Würbel H (2020) Reporting animal research: Explanation and elaboration for the ARRIVE guidelines 2.0. PLoS Biol 18(7):e3000411. https://doi.org/10.1371/journal.pbio.3000411

17. Johnson JH (1975) Effects of local irritation and dextran and sufphat administration on the periodontium of the rat. J Periodontal Res 10:332-345. https://doi.org/10.1111/j.1600-0765.1975.tb00042.x

18. de Almeida JM, Theodoro LH, Bosco AF, Nagata MJH, Oshiiwa M, Garcia VG (2007) Influence of photodynamic therapy on the development of ligature-induced periodontitis in rats. J Periodontol 78:566-575. https://doi.org/10.1902/jop.2007.060214

19. de Almeida JM, Theodoro LH, Bosco AF, Nagata MJ, Bonfante S, Garcia VG (2008) Treatment of Experimental Periodontal Disease by Photodynamic Therapy in Rats with Diabetes. J Periodontol 79:2156-2165. https://doi.org/10.1902/jop.2008.080103 
20. de Almeida J, Ervolino E, Bonfietti LH, Novaes VC, Theodoro LH, Fernandes LA, Martins TM, Faleiros PL, Garcia VG (2015) Adjuvant therapy with Sodium Alendronate for the Treatment of Experimental Periodontitis in Rats. J Periodontol 86:1166-1175. https://doi.org/10.1902/jop.2015.150166

21. Matheus HR, Ervolino E, Faleiros PL, Novaes VCN, Theodoro LH, Garcia VG, de Almeida JM (2018) Cisplatin chemotherapy impairs the peri-implant bone repair around titanium implants: An in vivo study in rats. J Clin Periodontol 45:241-252. https://doi.org/10.1111/jcpe.12824

22. Park CH, Abramson ZR, Taba MJR, Jin Q, Chang J, Kreider JM, Goldstein SA, Giannobile WV (2007) Threedimensional micro-computed tomographic imaging of alveolar bone in experimental bone loss or repair. $J$ Periodontol 78:273-281. https://doi.org/10.1016/j.jcma.2017.11.002

23. Zuza EP, Garcia VG, Theodoro LH, Ervolino E, Favero LFV, Longo M, Ribeiro FS, Martins AT, Spolidorio LC, Zuanon JAS, de Toledo BEC, Pires JR (2018) Influence of obesity on experimental periodontitis in rats: histopathological, histometric and immunohistochemical study. Clin Oral Investig 22:1197-1208. https://doi.org/10.1007/s00784017-2207-y

24. Garcia VG, Gualberto Júnior EC, Fernandes LA, Bosco AF, Hitomi Nagata MJ, Casatti CA, Ervolino E, Theodoro LH (2013) Adjunctive antimicrobial photodynamic treatment of experimentally induced periodontitis in rats with ovariectomy. J Periodontol 84:556-565. https://doi.org/10.1902/jop.2012.120163

25. Garcia VG, Longo M, Gualberto Júnior EC, Bosco AF, Nagata MJH, Ervolino E, Theodoro LH (2014) Effect of the concentration of phenothiazine photosensitizers in antimicrobial photodynamic therapy on bone loss and the immune inflammatory response of induced periodontitis in rats. J Periodontal Res 49:584-594.

https://doi.org/10.1111/jre.12138

26. Graves DT, Cochran D (2003) The contribution of interleukin-1 and tumor necrosis factor to periodontal tissue destruction. J Periodontol 74:391-401. https://doi.org/10.1902/jop.2003.74.3.391

27. Raghu Nadhanan R, Abimosleh SM, Su YW, Scherer AM, Howarth GS, Xian CJ (2012) Dietary emu oil supplementation suppresses 5-fluorouracil chemotherapy-induced inflammation, osteoclast formation, and bone loss. Am J Physiol Endocrinol Metab 302:E1440-E1449. https://doi.org/10.1152/ajpendo.00587.2011

28. Stine KC, Wahl EC, Liu L, Skinner RA, Vanderschilden J, Bunn RC, Montgomery CO, Suva LJ, Aronson J, Becton DL, Nicholas RW, Swearingen CJ, Lumpkin CK Jr (2014) Cisplatin inhibits bone healing during distraction osteogenesis. J Orthop Res 32:464-470. https://doi.org/10.1002/jor.22527

29. Graves D (2008) Cytokines that promote periodontal tissue destruction. J Periodontol 79:1585-1591. https://doi.org/10.1902/jop.2008.080183

30. Graves DT, Li J, Cochran DL (2011) Inflammation and uncoupling as mechanisms of periodontal bone loss. J Dent Res 90:143-153. https://doi.org/10.1177/0022034510385236

31. Preshaw PM, Taylor JJ (2011) How has research into cytokine interactions and their role in driving immune responses impacted our understanding of periodontitis? J Clin Periodontol 38:60-84.

https://doi.org/10.1111/j.1600-051X.2010.01671.x

32. Hamouda N, Sano T, Oikawa Y, Ozaki T, Shimakawa M, Matsumoto K, Amagase K, Higuchi K, Kato S (2017) Apoptosis, Dysbiosis and Expression of Inflammatory Cytokines are Sequential Events in the Development of 5Fluorouracil-Induced Intestinal Mucositis in Mice. Basic Clin Pharmacol Toxicol 121:159-168.

https://doi.org/10.1111/bcpt.12793

33. de Araújo AA, Varela H, de Medeiros CA, Brito GAC, de Lima KC, de Moura LM, de Araújo Júnior RF (2015) Azilsartan reduced TNF- $\alpha$ and IL-1 $\beta$ levels, increased IL-10 levels and upregulated VEGF, FGF, KGF, and TGF-a in an oral mucositis model. PLoS One 17:10:e0116799. https://doi.org/10.1371/journal.pone.0116799

Page $11 / 20$ 
34. Miller RP, Tadagavadi RK, Ramesh G, Reeves WB (2010) Mechanisms of Cisplatin nephrotoxicity. Toxins (Basel) 2:2490-2518. https://doi.org/10.3390/toxins2112490

35. Wisniewska-Jarosinska M, SliwinskI T, Kasznicki J, Krupa R, Bloch K, Drzewoski J, Chojnacki J, Blasiak J, Morawiec-Sztandera (2011) A Cytotoxicity and genotoxicity of capecitabine in head and neck cancer and normal cells. Mol Biol Rep 38:3679-3688. https://doi.org/10.1007/s11033-010-0482-7

36. Cho JM, Manandhar S, Lee HR, Park HM, Kwak MK (2008) Role of the Nrf2-antioxidant system in cytotoxicity mediated by anticancer cisplatin: Implication to cancer cell resistance. Cancer Lett 260:96-108. https://doi.org/10.1016/j.canlet.2007.10.022

37. Mailand N, Gibbs-Seymour I, Bekker-Jensen S (2013) Regulation of PCNA-protein interactions for genome stability. Nat Rev Mol Cell Biol 14:269-282. https://doi.org/10.1038/nrm3562

38. Mukhopadhyay S, Panda PK, Sinha N, Das DN, Bhutia SK (2014) Autophagy and apoptosis: where do they meet? Apoptosis 19:555-566. https://doi.org/10.1007/s10495-014-0967-2

39. Al-Mahalawy H, Marei HF, Abuohashish H, Alhawaj H, Alrefaee M, Al-Jandan B (2016) Effects of cisplatin chemotherapy on the osseointegration of titanium implants. J Craniomaxillofac Surg 44:337-346. https://doi.org/10.1016/j.jcms.2016.01.012

40. Ahluwalia A, Tarnawski AS (2012) Critical role of hypoxia sensor-HIF-1a in VEGF gene activation. Implications for angiogenesis and tissue injury healing. Curr Med Chem 19:90-97.

https://doi.org/10.2174/092986712803413944

41. Wang Y, Wan C, Deng L, Liu X, Cao X, Gilbert SR, Bouxsein ML, Faugere MC, Guldberg RE, Gerstenfeld LC, Haase VH, Johnson RS, Schipani E, Clemens TL (2007) The hypoxia-inducible factor alpha pathway couples angiogenesis to osteogenesis during skeletal development. J Clin Invest 117:1616-1626. https://doi.org/10.1172/JCl31581

42. Schmidt-Bleek K, Schell H, Lienau J, Schulz N, Hoff P, Pfaff M, Schmidt G, Martin C, Perka C, Buttgereit F, Volk HD, Duda G (2014) Initial immune reaction and angiogenesis in bone healing. J Tissue Eng Regen Med 8:120130. https://doi.org/10.1002/term.1505

43. Garlet GP (2010) Destructive and protective roles of cytokines in periodontitis: a re-appraisal from host defense and tissue destruction viewpoints. J Dent Res 89:1349-1363. https://doi.org/10.1177/0022034510376402

\section{Tables}

Table 1: Scores and specimens' distribution according to the parameters of the histologic analysis in sach group and time.

\section{Figures}




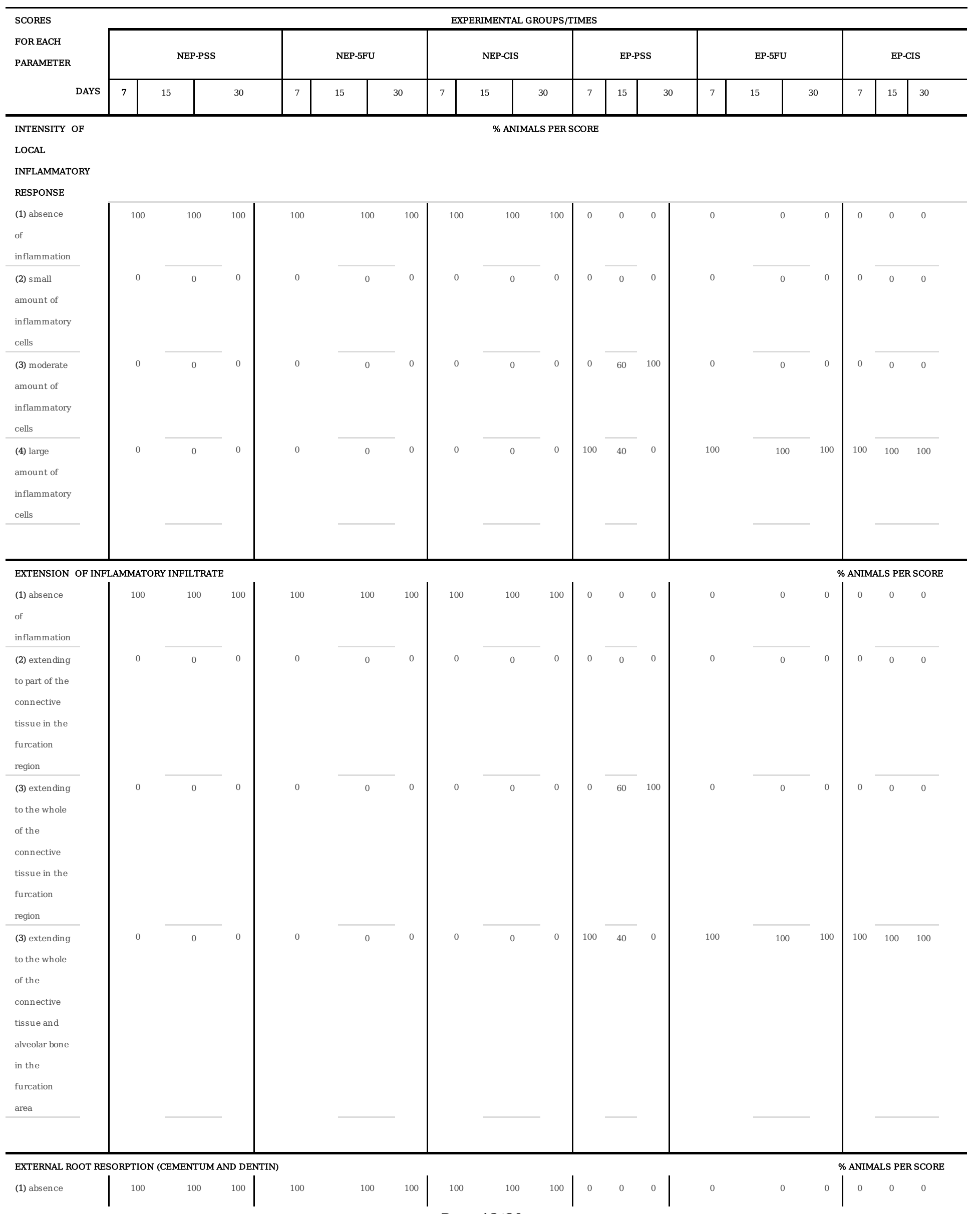

Page 13/20 


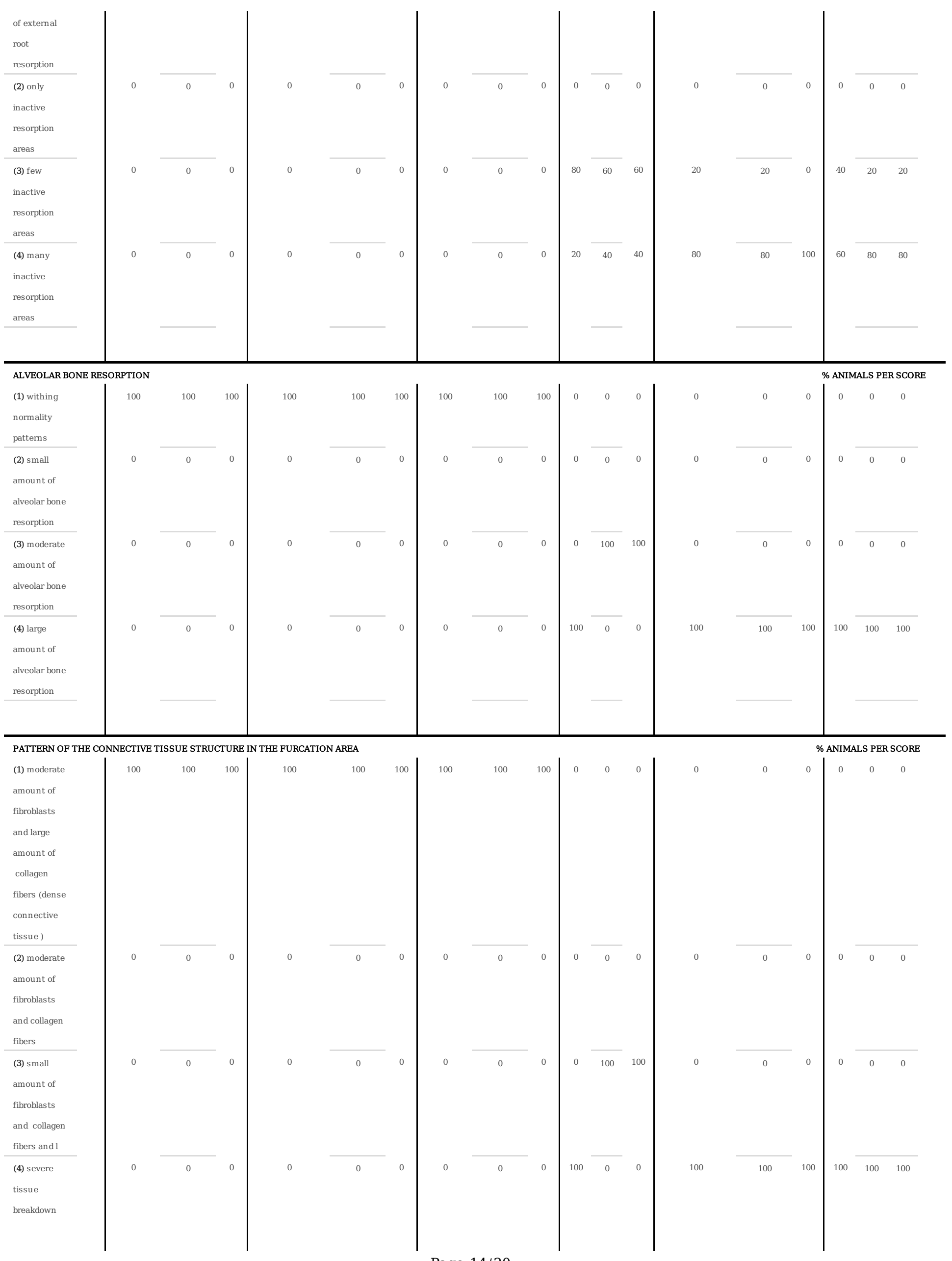

Page $14 / 20$ 


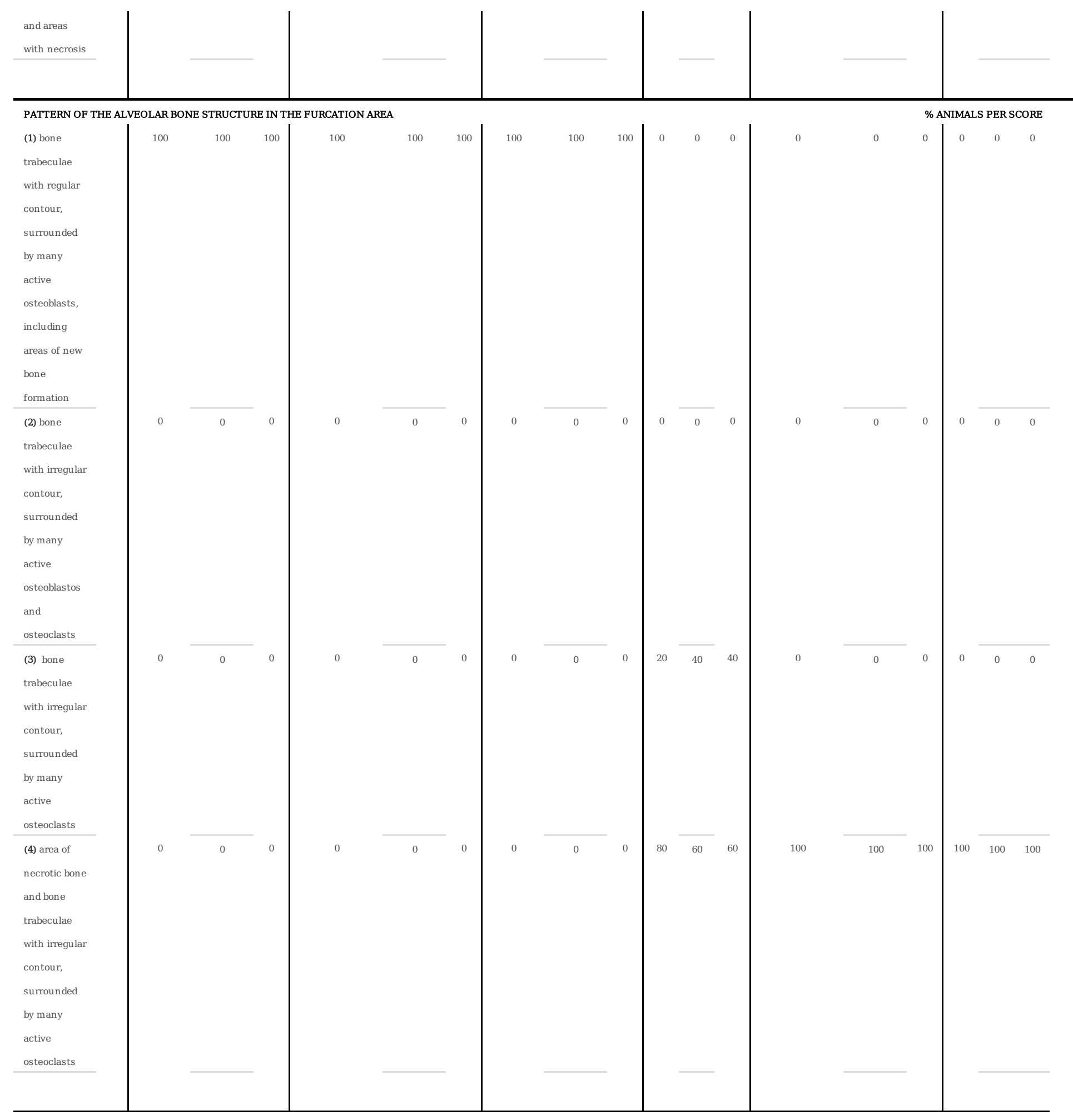

Page $15 / 20$ 

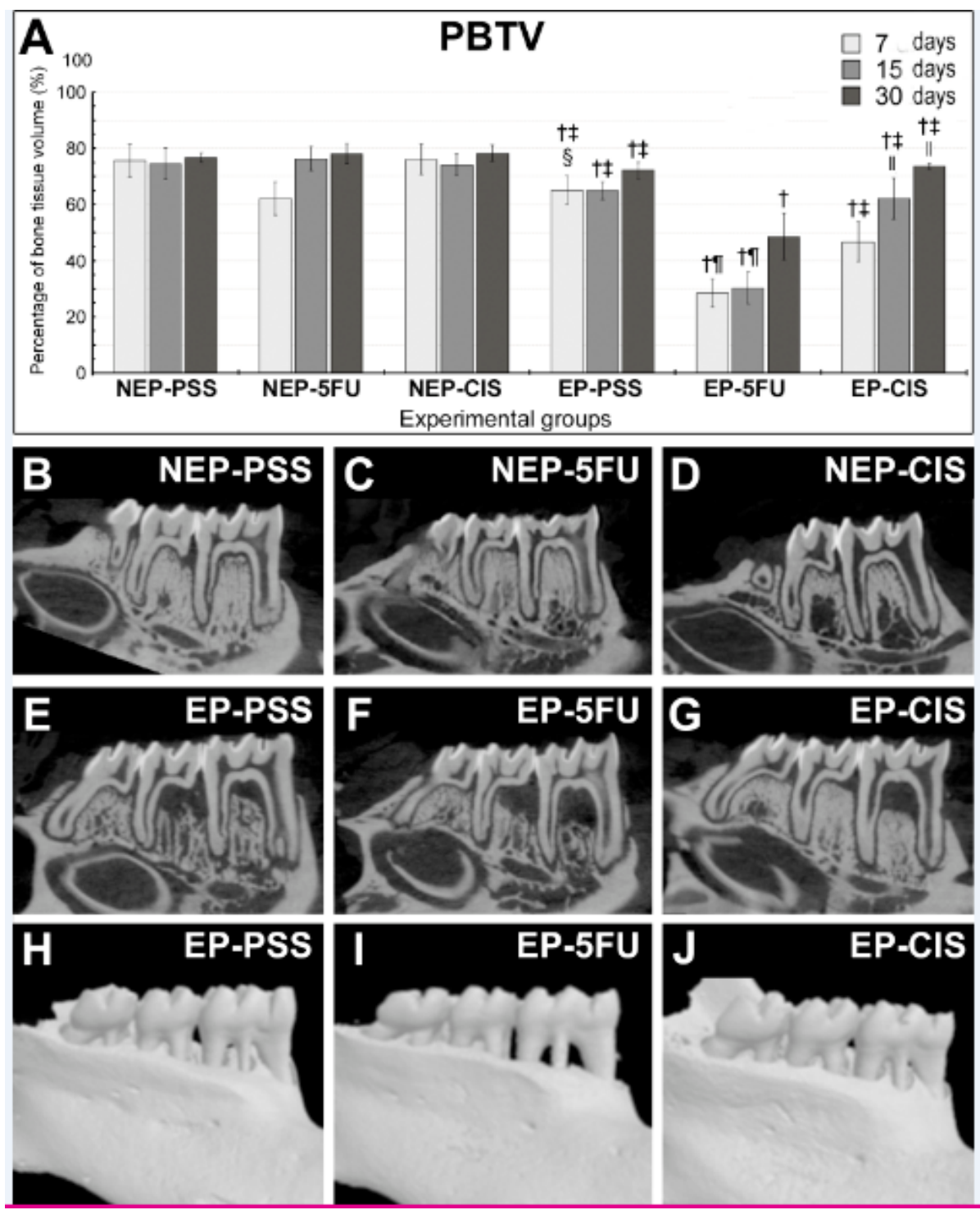

Figure 1

A: Graph showing the mean \pm standard deviations $(M \pm S D)$ of the PBTV in the furcations of the lower first molars. Symbols: 9 , statistically significant difference with 30 days at the same group; $\|$, statistically significant difference with 7 days at the same group; $†$, statistically significant difference with NEP-PSS at the same time points; $\neq$, statistically significant difference with EP-5FU at the same time points; §, statistically significant difference with EPCIS at the same time points. Statistical test: ANOVA and Tukey's test ( $p \leq 0.05)$. B-D: $\mu C T$ images for PBTV analysis in the furcations of the lower first molars in groups NEP-PSS, NEP-5FU and NEP-CIS at 7 days. E-G: $\mu$ CT images for PBTV analysis in the furcations of the lower first molars in groups EP-PSS, EP-5FU and EP-CIS at 7 days. Note the lack of bone filling the furcation of the animals that received either 5-FU or CIS. H-J: tridimensional images of the groups EP-PSS, EP-5FU and EP-CIS at 30 days. 

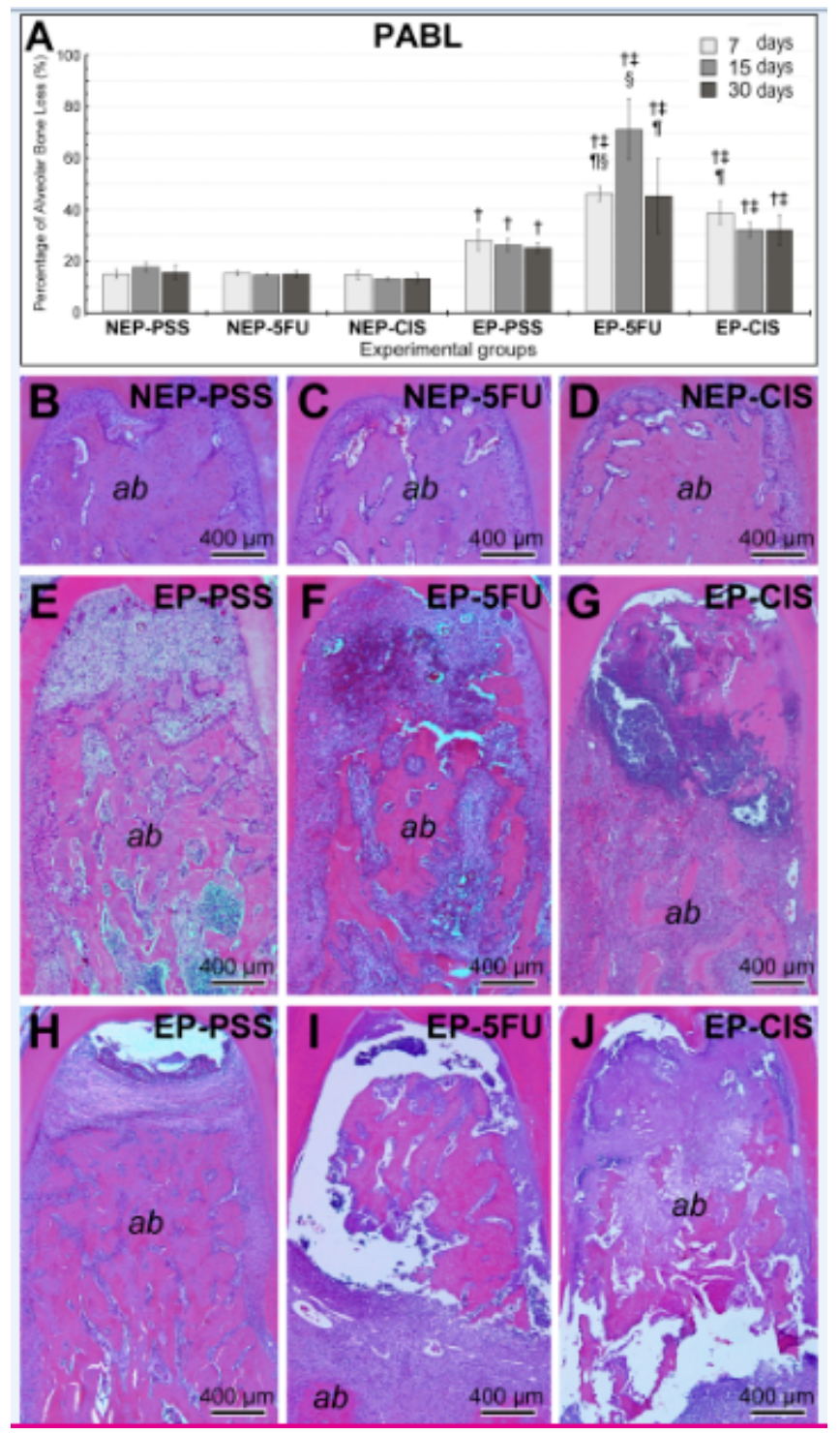

\section{Figure 2}

A: Graph showing the mean \pm standard deviations $(M \pm S D)$ of the PABL in the furcations of the lower first molars. Symbols: 9 , statistically significant difference with 15 days at the same group; $\dagger$, statistically significant difference with NEP-PSS at the same time points; $\neq$, statistically significant difference with EP-PSS at the same time points; $\S$, statistically significant difference with EP-CIS at the same time points. Statistical test: ANOVA and Tukey's test ( $p$ $\leq 0.05)$. B-D: photomicrographs showing the effects of the antineoplastics agents on healthy periodontal tissues. Periodontium in the furcation region of the lower first molars in animals that received PSS (B), 5-FU (C) or CIS (D). E$\mathrm{J}$ : photomicrographs showing the effects of the antineoplastics agents on the progression of experimental periodontitis. Histopathologic features at 7 and 30 days $(E / H)$ in the furcation region of the lower first molars in animals with EP that received PSS. Histopathologic features at 7 and 30 days in the furcations region of the lower first molars in animals with EP that received 5-FU (F/I) or CIS (G/J). Abbreviation: ab, alveolar bone. Staining: Haematoxylin and Eosin. Scale bars: $400 \mu \mathrm{m}$. 


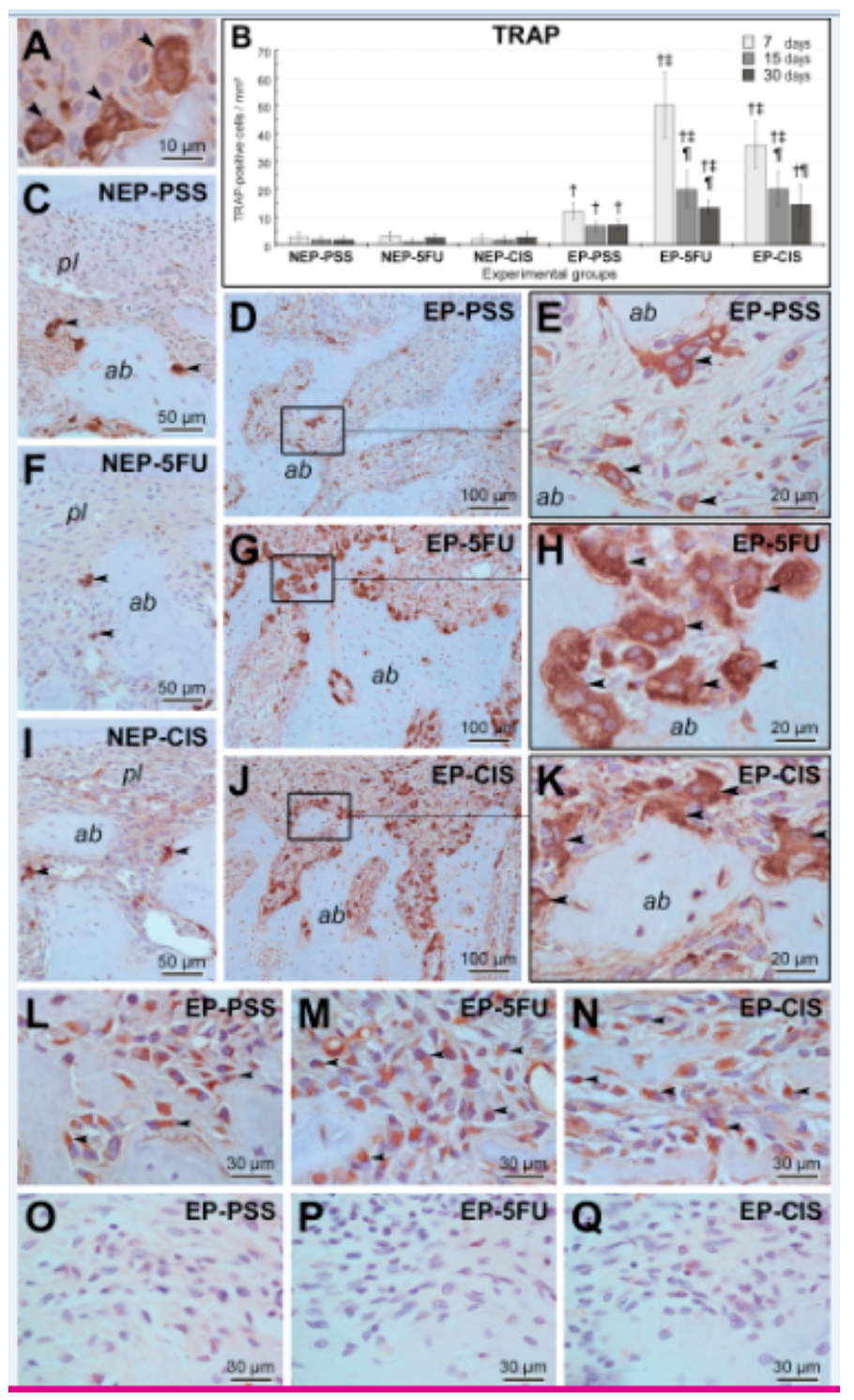

Figure 3

A: Immunolabelling pattern of TRAP in the furcation region of the lower first molars. B: Graph showing the mean \pm standard deviations (M \pm SD) of TRAP-positive cells for each group and period. Symbols: $\mathbf{9}$, statistically significant difference with 7 days at the same group; $\dagger$, statistically significant difference with NEP-PSS at the same time points; $\neq$, statistically significant difference with EP-PSS at the same time points. Statistical test: ANOVA and Tukey's test ( $p$ 50.05). C-K: Immunolabelling pattern of TRAP-positive cells at 7 days. Furcation region of the lower first molars in animals with EP that received PSS. L-M: photomicrographs of the immunolabelling pattern of RANKL-positive cells at 7 days. O-P: photomicrographs of the immunolabelling pattern of OPG-positive cells at 30 days. Furcation region of the lower first molars in animals that received PSS (C), 5-FU (F) or CIS (I). Furcation region of the lower first molars in animals with EP that received PSS (D, E, L, O), 5-FU (G, H, M, P) OR CIS (J, K, N, Q). Black arrows: TRAP-positive cells (A-K), RANKL-positive cells (L-M). Abbreviations: ab, alveolar bone; pl, periodontal ligament. Counter-staining: Harris' haematoxylin. Scale bars: A, $10 \mu \mathrm{m} ; \mathrm{E}, \mathrm{H}$ and K, $20 \mu \mathrm{m} ; \mathrm{L}-\mathrm{K}, 30 \mu \mathrm{m} ; \mathrm{C}, \mathrm{F}$ and I, $50 \mu \mathrm{m} ; \mathrm{D}, \mathrm{G}$ and J, $100 \mu \mathrm{m}$. 


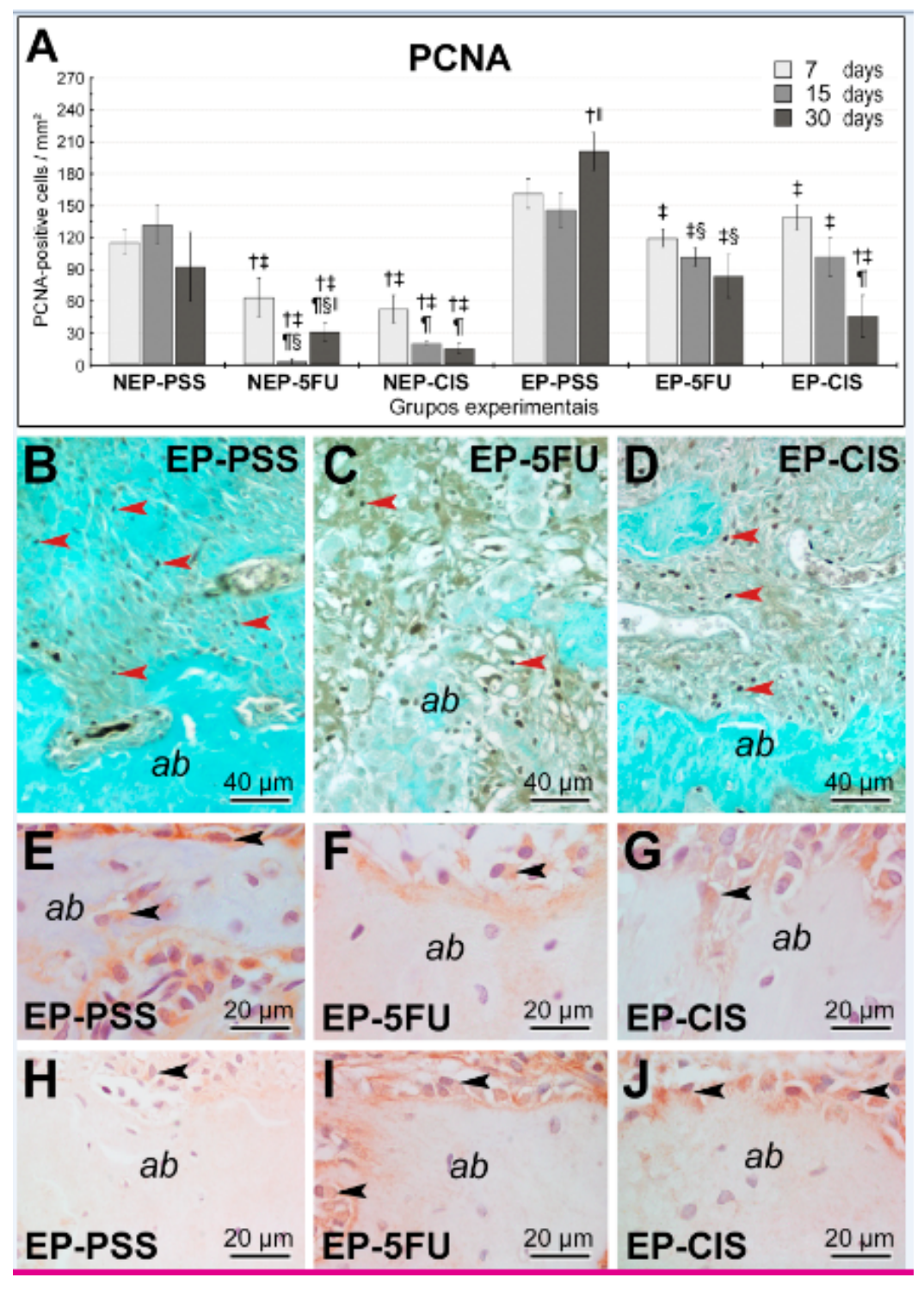

\section{Figure 4}

A-C: Photomicrographs showing the immunolabelling pattern of TNFa in the furcations region at 30 days. Furcation region of the lower first molars in animals that received PSS (A), 5-FU (B) or CIS (C). D-F: Photomicrographs showing the immunolabelling pattern of $\mathrm{IL}-1 \beta$ in the furcations region at 15 days. Furcation region of the lower first molars in animals that received PSS (D), 5-FU (E) or CIS (F). Black arrows: TNFa-positive cells (A-C), IL-1 $\beta$-positive cells (D-F). Abbreviation: ab, alveolar bone. Counter-staining: Harris' haematoxylin. Scale Bars: $100 \mu \mathrm{m}$. 

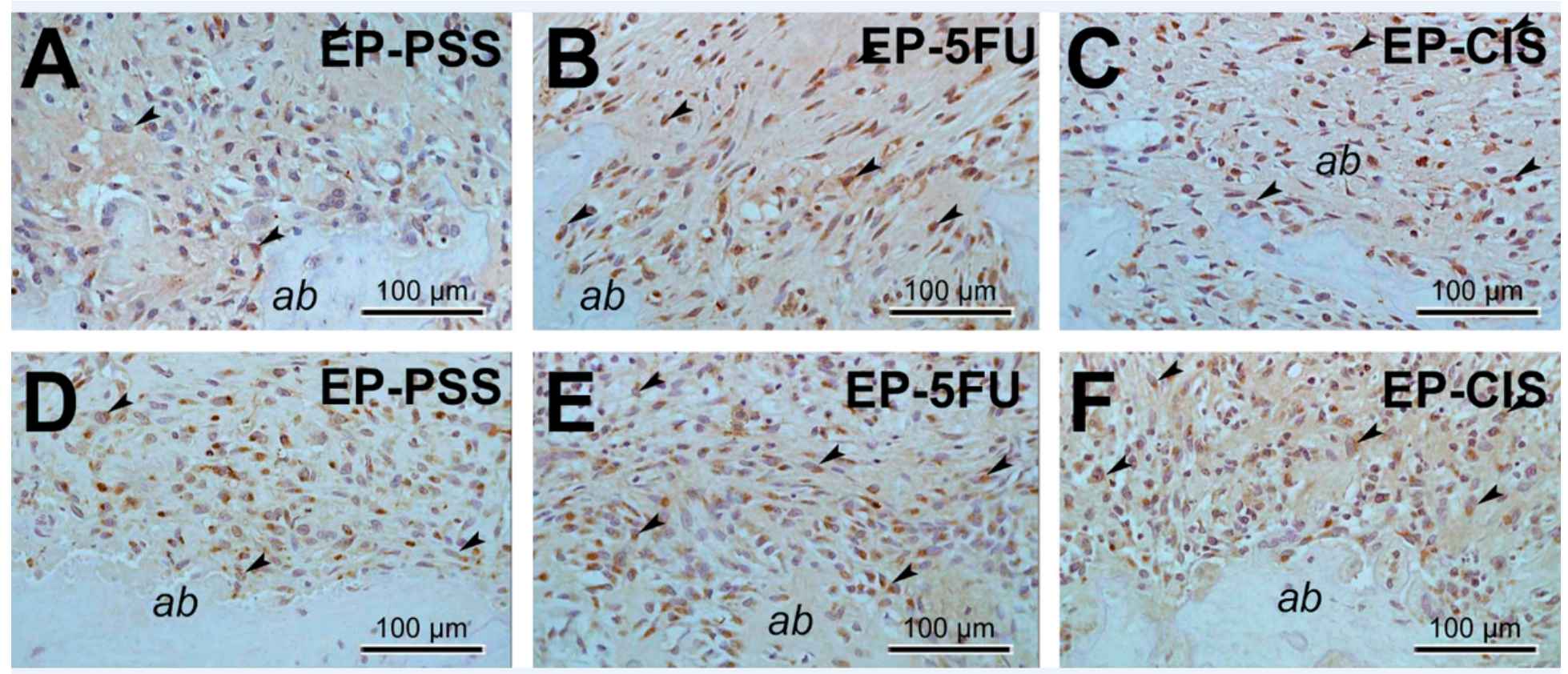

Figure 5

A: Graph showing the mean \pm standard deviations $(M \pm S D)$ of PCNA-positive cells for each group and period. Symbols: $\mathbf{9}$, statistically significant difference with 7 days at the same group; ll, statistically significant difference with 15 days at the same group; $†$, statistically significant difference with NEP-PSS at the same time points; $\neq$, statistically significant difference with EP-PSS at the same time points; §, statistically significant difference with NEP-CIS at the same time points. Statistical test: ANOVA and Tukey's test ( $p \leq 0.05)$. B-D: Immunolabelling pattern of PCNA-positive cells at 7 days. E-G: photomicrographs of the immunolabelling pattern of HIF-1a-positive cells at 15 days. $\mathrm{H}-\mathrm{J}$ : photomicrographs of the immunolabelling pattern of BAX-positive cells at 15 days. Furcation region of the lower first molars in animals with EP that received PSS (B, E, H), 5-FU (C, F, I) or CIS (D, G, J). Blue arrows: PCNApositive cells. Black arrows: HIF-1a-positive cells; BAX-positive cells. Abbreviation: ab, alveolar bone. Conter-staining: Abreviation: ab, alveolar bone. Counter-staining: Fast green (B-D); Harris' haematoxylin (E-J). Scale bars: B-D, $40 \mu \mathrm{m}$; E-J, 20

\section{Supplementary Files}

This is a list of supplementary files associated with this preprint. Click to download.

- AuthorChecklistE10onlyNovaes.pdf 